\title{
Canarias en las publicaciones periódicas francesas de la segunda mitad del siglo XIX
}

Cristina G. de Uriarte y José M. Oliver

\section{OpenEdition}

\section{Journals}

Edición electrónica

URL: https://journals.openedition.org/cher/518

DOI: 10.4000/cher.518

ISSN: 2803-5992

\section{Editor}

Presses universitaires de Strasbourg

\section{Edición impresa}

Fecha de publicación: 10 junio 2021

Paginación: 101-121

ISBN: 9791034400928

ISSN: 1968-035X

\section{Referencia electrónica}

Cristina G. de Uriarte y José M. Oliver, «Canarias en las publicaciones periódicas francesas de la segunda mitad del siglo xIx», reCHERches [En línea], 26 | 2021, Publicado el 15 septiembre 2021, consultado el 19 noviembre 2021. URL: http://journals.openedition.org/cher/518 ; DOI: https://doi.org/ 10.4000/cher.518 


\title{
Canarias en las publicaciones periódicas francesas de la segunda mitad del siglo XIX
}

\author{
CRISTINA G. DE URIARTE* \\ JOSÉ M. OLIVER ${ }^{* *}$
}

$\mathrm{E}_{\mathrm{l}}^{\mathrm{l}}$ singular emplazamiento del archipiélago canario en la encrucijada de las rutas transatlánticas no solo ha favorecido la creación y desarrollo de distintos mitos relacionados con su condición insular y su ubicación en los límites del mundo conocido, sino también ha constituido, desde la Antigüedad, un poderoso reclamo para los navegantes. En efecto, su utilización tradicional como lugar de avituallamiento ha propiciado, tras su "redescubrimiento» ${ }^{1}$ en las postrimerías de la Edad Media, el paulatino conocimiento y el estudio de las características etnográficas, geológicas, botánicas, zoológicas o climáticas de las Islas. Su carácter volcánico, la presencia del Teide -considerado durante siglos por los navegantes como la montaña más elevada del globo y un faro en el océano- o la tradición de situar el meridiano, primero en la isla de El Hierro -la más occidental de las Canarias- y luego en el Pico de Tenerife, son algunos de los motivos que atraen a muchos de sus visitantes.

* Cristina G. de Uriarte, Universidad de La Laguna. Grupo de Investigación Fran-Can. ORCID: 0000-0002-6448-752X, <curiarte@edu.ull.es>.

** José M. Oliver, Universidad de La Laguna. Grupo de Investigación Fran-Can. ORCID: 0000-0003-1263-8274, <joliver@edu.ull.es>.

1 El llamado «redescubrimiento» de Canarias alude al proceso de reconocimiento histórico del Archipiélago que empieza a tomar cuerpo, a partir del siglo XIV, con los viajes del genovés Lancelloto Malocello (1336), del portugués Nicoloso da Recco (1341) o de algunas misiones evangelizadoras que llevaron a cabo desde 1342 frailes mallorquines y catalanes y prosigue en 1402 con la conquista emprendida por Jean de Béthencourt y Gadifer de la Salle en nombre de Enrique III de Castilla. Igualmente, contribuyó a ello la representación de las Islas en distintos documentos cartográficos, como el portulano de Dulcert (1339) o la carta de los hermanos Pizzigani (1367), sin olvidar las menciones encontradas en distintos relatos de exploración. De la numerosa bibliografía existente a este respecto, destacamos, entre otros, los trabajos de Serra Ràfols (1961), Ladero Quesada (1979), Aznar Vallejo (2006) y Quartapelle (2017). 
El paso del tiempo no disminuye el interés por estas tierras, que siguen llamando la atención de insignes naturalistas, geógrafos, historiadores, antropólogos, astrónomos o médicos europeos, que, a menudo, las recorren auspiciados por entidades científicas, coincidiendo, ocasionalmente, ya en las últimas décadas del siglo XIX, con los primeros turistas. Por lo que respecta a los viajeros franceses, su afluencia es especialmente relevante en los siglos XVIII y XIX, no en vano algunos de los testimonios y estudios más sobresalientes sobre el Archipiélago se deben a ilustres personajes que ya forman parte indiscutible de la historia insular, como Louis Feuillée, Jean-Charles Borda, André-Pierre Ledru, Jean-Baptiste Bory de Saint-Vincent, Sabin Berthelot, Adolphe Coquet o René Verneau, entre otros ${ }^{2}$. De su estancia en las Islas se conserva un conjunto de materiales constituido por relatos de viajes, memorias científicas, correspondencia personal y oficial o informes diversos, además de numerosos grabados, mapas y fotografías, que conforman un legado de indiscutible valor no solo para Canarias, sino también para el conocimiento científico en general.

Como es sabido, el viaje y sus diferentes formas de expresión escrita conoce un extraordinario auge en los siglos xVIII y xIx, haciendo que las noticias relacionadas con los viajeros y sus expediciones adquieran una notable relevancia. La principal vía de difusión de estas informaciones es la edición, bien en forma de libro, bien en forma de artículos o textos de distinta naturaleza en publicaciones periódicas. En este último caso, además de la inmediatez informativa, se pone de manifiesto una mayor cercanía al lector, que lo mismo puede asistir al debate suscitado tras una comunicación recogida en las actas de una reunión académica como esperar impaciente la siguiente entrega de una narración ya iniciada o descubrir textos y dibujos aún inéditos. A este respecto, es de destacar la cantidad y variedad de revistas en las que los viajes, los viajeros y los lugares visitados cobran un especial protagonismo ${ }^{3}$. Así, junto a las editadas por las instituciones oficiales -que organizan las expediciones y difunden sus resultados- y las vinculadas a las sociedades científicas se suman, ya en el siglo XIX, otros proyectos editoriales de carácter periódico y eminentemente divulgativo, que, con nombres evocadores, están destinados a un lector cada vez más numeroso y heterogéneo ${ }^{4}$. No pocas de estas publicaciones han pervivido -con su título original o no- hasta hoy en día. A un primer tipo pertenecen los distintos ejemplares que edita el Muséum d'Histoire naturelle, los Comptes rendus de l'Académie des sciences o la Revue maritime et coloniale del Ministerio de la Marina; al segundo, el Bulletin de la Société de Géographie o el Journal des

2 Para más detalles sobre los viajeros franceses y sus expediciones a Canarias remitimos a los trabajos de Pico, Corbella, G. de Uriarte, Curell et al. (2000), G. de Uriarte (2006), Oliver y Relancio (2007), Relancio Menéndez y Ruiz Pacheco (2007), Oliver (2007) o Le Brun (2016).

3 A este respecto, véanse, por ejemplo, los trabajos de Bacot (2005), Martin (2007) y Venayre (2007).

4 Sobre esta clase de prensa, aconsejamos la lectura de los estudios de Feyel (2001), Aurenche (2002), Marcil (2006a y 2006b) o Huerta (2007), entre otros. 
voyages $\mathrm{y}$, finalmente, entre las revistas dirigidas a un público no especializado y que proliferan sobre todo en la segunda mitad del siglo xIx, figuran los Annales des voyages, Le Magasin pittoresque, L'Illustration, Le Journal illustré, Le Tour du monde, nouveau journal des voyages, la Revue des Deux Mondes o el Journal des Voyages et des aventures de terre et de mer. Recordemos que estas últimas experimentan un considerable desarrollo, propiciado, por una parte, por los avances técnicos y, por otra, por los profundos cambios sociales que tienen lugar a lo largo de la centuria. Además, la marcada vocación formativa y divulgadora de estas obras hace que los relatos y noticias de las exploraciones que se llevan a cabo -o se proyectan- por todo el globo ocupen un lugar más que destacado entre sus páginas, cuando no favorece la creación de revistas especializadas. Vemos, de esta manera, que las publicaciones periódicas no solo contribuyen al progreso científico con su inmediata difusión, sino también al reconocimiento de los autores antes incluso de la edición del relato en forma de libro (Marcil 2006b: 31). A esto hay que añadir que estos nuevos formatos, normalmente ilustrados, se benefician de los avances en el proceso de impresión, que permiten, entre otras cosas, incluir sugerentes imágenes litografiadas.

Justamente a esta categoría dedicamos nuestro trabajo ${ }^{5}$, en el que hemos examinado la presencia del archipiélago canario en revistas, anuarios o boletines franceses y la consecuente transmisión del conocimiento a que da lugar. Para ello hemos compilado un conjunto representativo de publicaciones, tanto en número como en línea editorial, y un periodo concreto, la segunda mitad del siglo XIX, centrándonos en los textos de carácter referencial y dejando de lado los pertenecientes a la ficción, así como las informaciones sobre Canarias que constituyen meras alusiones o indicaciones bibliográficas.

La labor de indagación que hemos llevado a cabo nos ha permitido identificar y clasificar más de treinta referencias en una veintena de revistas. Sin pretensión de exhaustividad y conscientes, por tanto, de la más que posible existencia de testimonios que no están incluidos en este estudio, consideramos, no obstante, que el corpus que aquí presentamos es lo bastante representativo. Los autores son principalmente experimentados viajeros y hombres de ciencia, la mayoría pertenecientes a diferentes sociedades científicas, aunque también hay entre ellos militares, médicos o periodistas. Sus textos, de contenido heterogéneo, adoptan la forma de notas, cartas, extractos, resúmenes, conferencias, reseñas, informes o anécdotas que se acompañan, a menudo, de dibujos.

Teniendo en cuenta su carácter y procedencia, podemos distinguir dos tipos de documentos, que presentaremos por orden cronológico. Así, y siguiendo la definición tradicional de relato de viajes, según la cual este es el resultado de la

5 Esta contribución se enmarca en el proyecto de investigación Representaciones de Canarias en la literatura y las artes en el que colaboramos y que financia el Ministerio español de Ciencia, Innovación y Universidades a través de la Universidad de La Laguna (convocatoria de Ayudas a nuevos proyectos de investigación, 2019). 
experiencia propia de un desplazamiento narrado en primera persona ${ }^{6}$, destaca un primer grupo que contiene aquellos textos sobre Canarias que son producto de la estancia en las Islas de sus autores; como veremos, en unas ocasiones el testimonio está centrado en un momento o acontecimiento relevante del viaje, mientras que en otras recoge diferentes impresiones de las tierras visitadas. Un segundo grupo está formado por aquellas informaciones extraídas de diversas fuentes y que no son resultado de la experiencia de quien las firma; en él se integran también otros materiales, tales como reseñas de libros o de campañas efectuadas y anuncios de otras próximas, estudios sobre diferentes aspectos antropológicos, históricos o sencillamente curiosos, y cuya presencia se debe a un intento de captar y mantener el interés del lector.

\section{Testimonios directos}

Un primer ejemplo nos lo proporciona el capitán Théophile Aube, oficial de la Marina y gobernador de la Martinica, que realiza diferentes campañas marítimas por todo el mundo. Durante una de ellas, cuyo destino es Senegal, hace una breve escala de avituallamiento en Santa Cruz de Tenerife en julio de 1859. Poco después regresa a la isla, donde permanece algo más de un mes, concretamente desde el 28 de septiembre de 1860 hasta el 2 de noviembre ${ }^{7}$. Bastantes años más tarde publica, en el número de agosto de 1876 de la Revue maritime et coloniale, "Notes sur les Canaries», un texto de una docena de páginas que contiene detallada información -obtenida en su mayor parte en el viceconsulado francés (Le Brun 2016: 392)- sobre la producción y el comercio de las Islas, sobre las líneas de vapores que las comunican con Europa y sobre su organización política, administrativa, militar, etc., pero que, sin embargo, carece de alusiones a su estancia o de comentarios de carácter personal. Nos permitimos, no obstante, destacar de su texto el elogio dedicado a Sabin Berthelot por su constante labor en pro de la extensión y consolidación de las conexiones marítimas con Francia:

Depuis quelques mois, il est vrai, sous l'impulsion énergique mais toute personnelle du consul de France, auquel il n'est que juste de rendre cet hommage

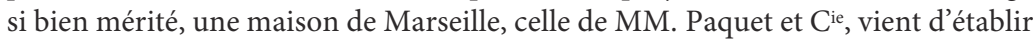
une ligne de bateaux à vapeur (Aube 1876: 340-341).

6 Sobre las características de la escritura del viaje, nos permitimos recomendar la lectura de los trabajos de Guentner (1997), Weber (2004), Magri-Mourgues (2009) o Le Huenen (2015), entre muchos otros.

7 Estas informaciones relativas a su paso por Canarias se encuentran en uno de sus libros, Entre deux campagnes, notes d'un marin (1881), en el que, por otra parte, no proporciona más detalles sobre el Archipiélago. La misión principal encomendada durante su segunda estancia consiste en reconocer el banco de Arguin y encontrar la isla de este nombre. En el no 33 de la Revue maritime et coloniale, aparecido en 1872, Aube publica «L'île d'Arguin et les pêcheries de la côte occidentale d'Afrique», donde recoge algunos datos sobre la pesca en Canarias y rememora los que le proporcionó el cónsul Sabin Berthelot. 
Otro testimonio procedente de un oficial francés se debe al también dibujante y reportero Achille Cibot, integrante de la campaña militar con destino a México iniciada en 1862. Durante su escala en Santa Cruz de Tenerife, redacta para el director de Le Monde illustré una carta, fechada el 7 de febrero de ese mismo año y publicada al mes siguiente, en la que le comunica, entre otras cosas, que le envía una vista de la ciudad -a partir de un croquis realizado por él mismo- y algunas impresiones rápidas del lugar, que en ese momento está animado por la presencia en el puerto de las naves francesas que se dirigen a la Martinica y a México. Aunque gran parte del contenido de la misiva consiste en comentarios triviales, el visitante hace una recomendación sobre los beneficios del clima insular, anuncio del turismo sanitario en ciernes8: "L'air est pur et vif dans ces îles fortunées, et je conseille fort aux personnes souffrantes d'aller y passer quelques années» (Cibot 20/03/1862: 208).

También en 1862 publica J. H. C. Curt una breve nota en La science pittoresque titulada «Les Iles Fortunées et le Pic de Ténériffe», en la que se hace eco de las bondades de la cumbre de la isla para la observación astronómica:

Cette île [Ténériffe] a été rendue célèbre par une haute montagne très-escarpée, connue sous le nom de Pic de Ténériffe [...]. C’est du sommet du Pic de Ténériffe, le point le plus élevé de toute l'Afrique, qu'on a pu constater avec plus d'exactitude la chaleur de la terre, et examiner avec plus de soin, grâce à l'extrême pureté du ciel, une foule de phénomènes météorologiques. Aussi, on vient de proposer d'ériger sur ce point un complet observatoire astronomique (Curt 21/02/1862: 395).

África es el destino del controvertido explorador Paul Soleillet, estrechamente vinculado al proceso de expansión colonial francesa y defensor de la creación de un ferrocarril transahariano. Llega al continente movido por razones personales: la muerte de su esposa y del hijo que esperaban, así como por la lectura de numerosos relatos de viajes (Valette 1980: 254). Después de haber visitado en tres ocasiones tierras africanas -en 1872-1873, 1873-1874 y 1878-, a finales de diciembre de 1879 embarca de nuevo al mando de una misión oficial con el fin de explorar las regiones entre Senegal, Malí y Argelia. Sus notas tomadas durante la campaña las publica en 1880, en forma de diario, en el Bulletin de la Société languedocienne de géographie, donde incluye unas breves referencias a Canarias, «populations européennes par leurs mœurs, et cependant de race africaine» (Soleillet 1880: 487), que aluden a su comercio y a las relaciones que mantienen Tenerife y Lanzarote con la colonia inglesa establecida al sur de Marruecos, en el Cabo Juby.

En este primer grupo de publicaciones se incluye, igualmente, la correspondencia personal. Un ejemplo lo encontramos en las cartas de Auguste Stahl -malogrado integrante de la expedición francesa de 1880 a Gabón9- que

8 Un año antes el político Gabriel de Belcastel publica una pequeña memoria sobre este asunto, véase Curell, Oliver y G. de Uriarte (2010).

9 Cuatro meses después de iniciar esta ansiada misión, cuyo objetivo consistía en establecer cerca del río Ogooué una colonia francesa, unas fiebres acaban con la vida del joven explorador. 
Émile Dietz, miembro de la Société académique du Bas-Rhin, da a conocer entre junio y septiembre de 1883 en el boletín de esta entidad, tras presentarlas en distintas reuniones de la misma ${ }^{10}$. El conjunto epistolar legado por este explorador conjuga, sin duda alguna, utilidad y amenidad, dos características igualmente esenciales en el relato de viajes. Stahl llega a Lanzarote, a bordo del Cygne, el 5 de diciembre de 1880, y su primera impresión es muy desfavorable:

L'île est montagneuse, volcanique, pelée. Arrecife est un sale petit port de rien du tout... Pourquoi les anciens appelaient-ils ces îles-ci les Iles Fortunées? La grande Canarie, avec ses nombreux cours d'eau justifierait peut-être ce surnom flatteur (Stahl apud Dietz 1883: 244-245).

Permanece en la isla casi dos semanas, dedicado a la adquisición de las caballerías necesarias y a su acomodo en el barco, tiempo durante el que tiene la oportunidad de apreciar sobre todo el calor y la sequía que asola esta tierra:

Quoique nous soyons en hiver la chaleur pendant le jour est très respectable [...] Le climat est d'ailleurs ici très sec, par conséquent très sain. Mais, helas! pourquoi pas d'eau? Triste pays sous ce rapport. En 1878, année où il n'a pas plu à Arrécife, les habitants de la ville furent obligés de déserter et d'aller dans les îles voisines [...] Le reste du temps l'eau est aussi bien que peut être l'eau conservée. Celle que je bois actuellement est tombée en mars. Depuis ce mois il n'est plus tombé une goutte à Arrécife [...] (Stahl apud Dietz 1883: 247).

Con el paso de los días, sin embargo, el viajero va apreciando algo de lo que la isla le ofrece, hasta el punto de confesar que le gusta el perfil acentuado de sus montañas (Stahl apud Dietz 1883: 246), así como el transporte en camello (Stahl apud Dietz 1883: 247), que utiliza para la excursión a las Montañas de Fuego, el insólito paraje volcánico que conoce gracias al notario Antonio Manrique y Saavedra, un hombre culto que chapurrea francés e inglés y al que dedica la última carta escrita desde las Islas.

El explorador Camille Douls hace escala en Canarias en 1886, durante su primer viaje a África. En el primer capítulo de su relación, publicada en forma de monografía poco después, en 1888, en Le Tour du monde, con el título de "Cinq mois chez les Maures nomades du Sahara occidental» y la aclaración de «texte et dessins inédits», aporta informaciones y dibujos sobre Tenerife, Gran Canaria y Lanzarote. Las primeras doce páginas contienen sus vivencias e impresiones canarias, que se acompañan de un mapa con el itinerario realizado y de cuatro dibujos. Así, Douls, tras describir los objetivos de su viaje (recorrer la región de Seguiat-El-Hamra y adentrarse en la provincia argelina de Tinduf), da cuenta de su arribada al puerto de la capital tinerfeña el 20 de diciembre, al tiempo que refleja algunos tópicos relativos al clima, a la exuberancia de su paisaje, a la belleza de las mujeres isleñas o a la fama de su vino:

10 En la primera entrega, Émile Dietz reproduce parte de la correspondencia enviada a los familiares, entre la que se incluye la carta en la que se comunica el detalle de las actividades de los últimos días con vida de Stahl y un fragmento de la necrológica. Un año después, Dietz (1884) recoge en un libro las vicisitudes del viaje africano de Stahl. 
Les îles Fortunées! C'est le seul nom qui convienne aux Canaries. Quant à moi, elles ont su tellement me captiver, que j'ai failli m'oublier sous leur ciel enchanteur. [...] Figurez-vous donc un bijou d'archipel où le thermomètre ne varie pas de toute l'année entre 20 et 28 degrés centigrades, où fleurit l'oranger et mûrissent le coco et la banane; de petites îles faites à souhait et qui résument toutes les merveilles de la création. On y voit de jolies femmes au teint mat et aux grands yeux noirs, et la nuit on s'endort au bruit de la sérénade; on y voyage en voiture et en dromadaire; on y boit d'un certain vin de malvoisie qu'un duc de Clarence aima autrefois, dit la légende, jusqu'à en mourir; et l'on y vit pour rien (Douls 1888: 178).

Buena parte de su relato se centra en los avatares y preparativos de su empresa, como cuando revela los intentos del cónsul de Francia, el barón René de Chassériau, por disuadirlo de su proyecto africano, por lo que, viendo que desde Tenerife le resulta imposible trasladarse al continente, se dirige a Las Palmas de Gran Canaria, donde tiene la ocasión de encontrarse con Gregorio Chil y Naranjo, director del Museo Canario, y con otros intelectuales, científicos y empresarios locales que lo disuaden igualmente de su aventura. Ante el empeño que manifiesta este explorador de tan solo veintidós años, le sugieren ir a Lanzarote, donde logra, no sin dificultades, que unos pescadores lo lleven finalmente a la costa sahariana a bordo del Adelaida, un pesquero de treinta y cinco toneladas y una tripulación de treinta marineros. El texto de Douls, que destila la frescura de la escritura en primera persona de un joven aventurero obsesionado con llevar a cabo su empresa, no sobrepasa lo anecdótico, como se puede apreciar al rememorar su llegada a Lanzarote:

Je descendis à l'unique hôtel de l'île je crois, un hôtel italien tenu par un certain Fumagallo. Je rencontrai l'hôtelier au port; il m'annonça que j'étais le seul étranger à Lanzarote et qu'il y avait plusieurs années qu'on n'y avait vu de Français. Aussi il me demanda, en m'offrant ses services, quel était l'objet qui m'amenait dans l'île. [...] Je ne cherchai pas à lui cacher mon projet. Il se tourna aussitôt vers moi pour voir si je parlais sérieusement. Ma gravité ne le lui laissa pas de doute. [...] A la fonda italiana on mangeait en famille; nous arrivâmes au moment du repas. Autour de la table, à côté de la patronne et des enfants, il y avait trois hôtes: le juge, un notaire et le colonel de l'armée territoriale. Pour jouir de l'étonnement général l'hôtelier me présenta d'un air mystérieux en annonçant que je voulais me faire déposer sur la côte et abandonner au milieu des Maures (Douls 1888: 180).

El antropólogo René Verneau, asiduo visitante del Archipiélago desde 1877 y autor de una abundante bibliografía sobre diferentes temas canarios -entre la que sobresale sus Cinq années de séjour aux Îles Canaries (1891)-, también se sirvió de las publicaciones periódicas francesas para ir dando a conocer sus investigaciones. Así, por ejemplo, redacta, para el Bulletin de géographie historique et descriptive, una síntesis de los estudios realizados durante su segundo viaje (1884-1887), que había expuesto en una sesión celebrada en el Ministère de l'Instruction publique el 22 de mayo. Verneau (1888a y 1888b) no solo presenta las características generales de cada una de las Islas y sus habitantes, sino que llama la atención del Gobierno francés sobre las ventajas 
que estas ofrecen desde el punto de vista comercial y turístico. Asimismo, resume sus conclusiones acerca del origen de la población del Archipiélago y responde a las preguntas de los asistentes, algunas de las cuales giran en torno al lenguaje silbado de La Gomera y a las que Verneau (1888a: 135) contesta con el relato de su experiencia personal, que inicia con las siguientes palabras: «Les doutes que je pouvais conserver à cet égard [...] ont été complètement levés au mois de mars 1878, à Valle-Gran-Rey» ${ }^{11}$. Unos años después, en enero de 1899, ofrece, a petición de la dirección de la Revue générale des sciences pures et appliquées, un pequeño artículo, con el título de «Le Maroc et les Canaries», cuya finalidad es permitir a los integrantes del octavo crucero que organiza esta revista hacerse una idea de estas dos regiones, toda vez que se constata una notable carencia bibliográfica sobre ellas. Por lo que respecta a nuestro archipiélago, Verneau proporciona una amplia información con gran profusión de datos. Junto a los detalles sobre su situación geográfica o las anotaciones sobre temas tan variados como la conquista, la orografía, el clima, los cultivos, la vegetación o la población, entre otros, encontramos afirmaciones que revelan su admiración por estas tierras y sus gentes:

Mais ce qui imprime à cette flore un cachet de grandeur imposant, ce sont les arbres des forêts canariennes [...] On reste stupéfait en présence de lauriers dont le tronc atteint jusqu'à 9 mètres de circonférence. [...] Leur honneteté [de los campesinos] est digne des plus grands éloges (Verneau 15/01/1899: 150-151).

En el número 1482, de junio de 1889, de Le Tour du monde, encontramos una muestra más del interés que suscita Tenerife como destino turístico. Se trata de la crónica que firma el viajero y periodista Edmond Cotteau dando cuenta de su estancia en la isla a finales del verano del año anterior: "Ascension au Pic de Ténériffe (Pic de Teyde)» (Pico 2007). Abundan en el texto, que se acompaña de cinco ilustraciones, las descripciones de pueblos y paisajes, de la flora o de las costumbres y fiestas que tiene ocasión de disfrutar, aunque es la excursión al Teide, como es lógico, la que acapara el grueso de su contribución. Así, por ejemplo, refiere la salida del sol desde la cima del volcán:

Un peu avant six heures, une tache sanglante surgit à l'horizon, qui se pare aussitôt des couleurs les plus éclatantes et les plus variées. Comment décrire ce magique tableau? Le disque de feu émerge de l'océan, ses premiers rayons illuminent d'une lueur rosée la cime du volcan; les sommités commencent à s'éclairer, tandis que les vallées restent encore plongées dans les ténèbres (Cotteau 1889: 350).

Unos días después, y tras visitar el Jardín de aclimatación de La Orotava invitado por el responsable de su cuidado, el suizo Hermann Wildpret, se dirige a Gran Canaria, donde hace también algunas excursiones, para embarcarse desde allí rumbo a Marsella. Gracias a la extensa difusión que le aseguraba la revista, el artículo de Cotteau tuvo una notable repercusión, hasta el punto de

11 Mucho más tarde, en 1923, Verneau publicaría, con el título de «Le langage sans paroles», un artículo sobre este tema. Existe versión española de Oliver y Curell (2007b). 
que suele ser objeto frecuente de recomendación para futuros visitantes. Valga destacar, asimismo, que Jules Verne se sirve profusamente de este texto a la hora de escribir el capítulo «Au sommet du Teyde» de su novela póstuma L'Agence Thompson \& $C^{\circ}$ (Oliver y Curell 2016).

El 25 de octubre de 1888 el ingeniero hidrógrafo Jean-Jacques Bouquet de la Grye lee, en la sesión pública anual del Institut y en su calidad de miembro de la Académie des sciences, una relación que, con el título de «Une ascension au Pic de Ténériffe», vería la luz en el Annuaire pour l’an 1889 publié par le Bureau des longitudes ${ }^{12}$. El autor llega a Tenerife, en misión oficial, con el encargo de realizar una serie de comprobaciones del cable telegráfico que tres años antes había comenzado a instalar entre Saint Louis (Senegal) y la capital tinerfeña. Su estancia en la isla, que se prolonga poco más de un mes, le permite, además, visitar las principales ciudades y -cómo no-realizar la excursión al Teide, cuya primera impresión le produce cierto desencanto:

La route d'Orotava au Teyde a été si fréquemment décrite, les difficultés ont été si souvent signalées dans toutes les langues, que le premier sentiment que l'on éprouve en la suivant est une déception (Bouquet de la Grye 1889: 743).

En su texto, que se lee con deleite, no solo se aprecia su sólida formación científica, sino también su amplia cultura y los conocimientos que sobre distintos aspectos de las Islas le han aportado diversas lecturas previas. Así, por ejemplo, rememora su pasado mitológico, evoca algunos hechos y personajes de la conquista o invita a investigar el lenguaje silbado de los pastores de La Gomera: «[...] il serait digne des philologues d'étudier ce langage presque historique conservé sur un sommet qui a pu appartenir à l'antique Atlantide» (Bouquet de la Grye 1889: 753).

Un testimonio epistolar más nos lo proporciona el naturalista y viajero infatigable Charles Alluaud, que el 26 de febrero de 1890 escribe una carta desde Las Palmas de Gran Canaria a la Société zoologique de France. El motivo de su segunda estancia ${ }^{13}$ en el Archipiélago es estudiar, principalmente, su entomología, para lo que reside durante varios meses primero en Gran Canaria y luego en Tenerife. La carta, que surge más de una necesidad personal que profesional, es leída en la sesión académica del 11 de marzo y reproducida ese mismo año en el boletín de la mencionada sociedad. Se trata de un documento que da cuenta del quehacer diario del científico y que muestra su entusiasmo por los resultados obtenidos, de los que da algunos detalles, y que espera completar: "J'ai l'espoir que nous pourrons ainsi jeter une certaine lumière sur bien des points encore obscurs de la zoologie de l'intéressant archipel des Canaries» (Alluaud 1890: 81). Incluso se permite alguna pincelada humorística, como

12 El mismo año y con el mismo título, el Institut de France publica, en formato de monografía, esta conferencia a través de la imprenta de Firmin-Didot et $C^{i e}$.

13 La primera tuvo lugar en 1883, con ocasión de su viaje de novios. Regresa en noviembre de 1889 y durante siete meses recorre todo el Archipiélago haciendo interesantes colecciones de insectos. 
cuando comenta que para sus desplazamientos utiliza el tradicional camello, lento y confortable, "permettant de bien voir le pays et de prendre au passage les insectes au vol. Quand il ne voit rien le zoologiste a encore la ressource de passer la main dans la toison du sympathique animal et d'y faire une ample récolte des parasites qui ont peut-être leur intérêt» (Alluaud 1890: 81).

En esos años el silbo se convierte en un tema recurrente entre los estudiosos, tanto locales como foráneos. El antropólogo Joseph Lajard es uno de ellos $y$, fruto de su estancia de varios meses en el Archipiélago, es el trabajo que presenta el 2 de julio de 1891 en la Société d'anthropologie parisina y que se publica poco después ${ }^{14}$. A lo largo de una quincena de páginas, Lajard repasa la bibliografía existente (empezando por el citado artículo de Bouquet de la Grye), analiza la producción de los sonidos silbados, su relación con las palabras guanches conocidas o las conclusiones a las que han llegado otros investigadores. Su riguroso estudio de campo, que contiene seis dibujos que representan las diferentes maneras de silbar, es uno de los primeros en llevar a cabo una pormenorizada descripción de la técnica material de este sistema de comunicación lingüística y en definir claramente su estatus: «Le langage sifflé des Canaries n'est pas un fait isolé. Nous avons vu qu'il n'est pas particulier au point de vue linguistique, car c'est de l'espagnol» (Lajard 1891: 482).

En los años siguientes aparecen en otras revistas varios trabajos sobre el mismo asunto, pero que no aportan nada nuevo, sino que más bien retoman la información proporcionada por autores anteriores (sobre todo Bouquet de la Grye, Verneau y Lajard). Es el caso de tres artículos diferentes, publicados dos en 1892 y otro en 1893, con el mismo título: "Le langage sifflé». Uno es obra de Louis Figuier, el más relevante divulgador científico francés del siglo XIX, y aparece en L'année scientifique et industrielle; otro se publica en Le Magasin pittoresque y está firmado por el Dr. C.T.; el último se debe al botánico Henri Coupin, que da a conocer su nota en un número de Le Monde illustré.

Concluimos este primer grupo, que hemos presentado por orden cronológico, con un testimonio del que disponemos de muy poca información. Nos referimos a la breve carta que redacta Dumast ${ }^{15}$ para la Société de géographie commerciale de Paris desde el Puerto de La Orotava el 3 de enero de 1896. Destinada a un lector que no hemos podido identificar, comienza recordando la promesa de escribir unas palabras a su llegada a Canarias. Los comentarios que siguen - «Malheureseument ce que je puis vous dire est peu intéressant pour la Société» (Dumast 1896: 51) - ofrecen una imagen negativa de las Islas, centrada en el comercio y en el Gobierno español. Del primero afirma que es casi inexistente y que de las viñas -arrancadas para producir la cochinilla y plantadas de nuevo

14 Existe versión española de Oliver y Curell (2007a).

15 La carta reproducida está firmada por «M. de Dumast», sin que se encuentre en la revista más aclaración sobre la identidad de este autor. Creemos que se trata del barón Charles-François-René Guerrier de Dumast (1858-1939), doctor en Derecho e historiador. 
al acabar la anilina con su cultivo- se obtiene un vino de poca calidad: «Il y a encore dans l'île trois ou quatre propriétaires qui font de la véritable Malvoisie. Les autres font des mixtures et des coupages» (Dumast 1896: 51). Y al segundo lo critica con dureza:

L'incurie espagnole est incroyable. La jetée du port de Santa-Cruz est commencée depuis de nombreuses années. Maintenant les travaux sont interrompus par ordre du gouvernement espagnol (toujours la centralisation!) qui, paraît-il, prétend que les plans sont mal faits et qu'il faut donner une autre direction à ladite jetée. Or, il faut une nouvelle grue à vapeur qu'on va construire en Espagne et pour la construction de laquelle on cherche des fonds! / En dehors de ça, rien à dire. [...] En d'autres mains que celles des Espagnols les Canaries seraient une colonie merveilleuse (Dumast 1896: 52).

El único aspecto positivo que resalta es la benignidad del clima: «J'ai fait absolument tout le tour de la Méditerranée, et n'ai trouvé nulle part [...] un climat si merveilleux pour y passer l'hiver» (Dumast 1896: 52).

\section{Testimonios indirectos}

Como ya señalamos, en otras ocasiones las informaciones sobre los viajes y los viajeros proceden de terceras personas y pueden adoptar diferentes formas. El número de estas reseñas, crónicas, informes, anuncios o notas no es nada desdeñable, ya que este tipo de textos es, además de habitual, imprescindible en la prensa periódica, tanto científica como de divulgación. A veces su finalidad consiste, sencillamente, en acusar recibo de objetos o de muestras naturales que se envían desde las Islas para ser analizadas, como se puede observar en una pequeña nota de L'Année scientifique et industrielle en la que se explica el origen sahariano de una muestra enviada desde Tenerife por Sabin Berthelot de:

[...] la pluie de sable qui est tombée sur une partie des îles Canaries, le 7 février 1863, pendant la nuit et la matinée du même jour, saupoudrant les navires devant Ténériffe, Palma et l'île de Fer. Le pic de Ténériffe alors couvert de neige, fut coloré en jaune jusqu'à son sommet, par cette poussière d'un grain presque impalpable (Figuier 1864: 279-280).

En otras ocasiones, el objetivo es reproducir documentos originales e inéditos para rescatarlos del olvido, pero también para anunciar futuras campañas, seguir de cerca el desarrollo de una expedición o acompañar al viajero y compartir con él las emociones que suscitan los éxitos alcanzados o los imprevistos, tanto en alta mar como en tierra. Así, por ejemplo, en la sección «Chronique géographique» de 1887 del Bulletin de la Société languedocienne de géographie se informa de que el intrépido Douls ha comunicado «les péripéties à la fois émouvantes et amusantes» de su viaje a África a la Société de géographie de París (Gachon 1887: 512-513); posteriormente, y siempre dentro de la misma sección, se anuncia su marcha al Sáhara (Malavialle 1888: 218 y 357) y su fallecimiento, asesinado por sus guías en el desierto (Malavialle 1889: 446). 
En 1867, Victor-Adolphe Malte-Brun, director de los Annales des voyages, firma una reseña sobre el libro La Guyane française. Notes et souvenirs d'un voyage exécuté en 1862-1863, publicado ese mismo año por el oficial de marina Frédéric Bouyer en la editorial Hachette. De la docena de páginas que ocupa la nota, cuatro están dedicadas a la escala en Canarias y en ellas encontramos reproducidas algunas impresiones del viajero, bien en alusión al Teide - «pour aller soi-même porter sa carte au sommet du colosse, il faut avoir tout le courage que donne l'amour de la science ou l'excentricité» (Malte-Brun 1867: 108)- bien referidas a Santa Cruz de Tenerife - «cette cité bâtie en amphithéâtre au bord de la mer, offre l'aspect pittoresque qui caractérise assez généralement toutes les villes hispano-américaines» (Malte-Brun 1867: 108). Sin embargo, es el recuerdo del avistamiento e intento de captura de un calamar gigante en aguas canarias el que ocupa, como es de esperar, casi todo el espacio y evoca de nuevo las palabras del marino francés:

Je me trouvais donc en présence d'un de ces êtres bizarres que la mer extrait parfois de ses profondeurs comme pour porter un défi aux naturalistes. L'occasion était trop inespérée et trop belle pour ne pas me tenter. Aussi eus-je bien vite pris la résolution de m'emparer du monstre, afin de l'étudier de plus près. [...] Longtemps je retrouverai fixé sur moi ce regard vitreux et atone, et je sentirai ces huit bras qui m'enlacent dans leurs replis de serpents: longtemps je garderai la mémoire du monstre rencontré par l'Alecton le 30 novembre 1861, à 2 heures de l'après-midi, à 40 lieues dans le nord-est de Ténériffe (Malte-Brun 1867: 105-107).

Diferentes revistas se hacen eco de este singular hallazgo, que reproducen en términos similares. Entre ellas figuran el Almanach du Magasin pittoresque (Charton 1863: 40) o Le Magasin pittoresque (Charton 1872: 338). A través de L'Année scientifique et industrielle (Figuier 1863: 288-291) sabemos que el cónsul de Francia, Sabin Berthelot, envía a la Académie des sciences parisina un dibujo en color del cefalópodo y un informe sobre lo ocurrido, que esta publicación reproduce. Bouyer, por su parte, redacta otro desde Santa Cruz de Tenerife para el ministro de Marina, que es leído en la Académie des sciences y posteriormente es recogido en sus Comptes rendus hebdomadaires des séances de l'Académie des sciences (1861: 1263-1265). A este texto le sigue una nota que, desde Tenerife, envía Berthelot sobre este mismo asunto (1861: 1265-1267).

Édouard Charton, fundador del semanario Le Magasin pittoresque, publica en 1873 una recensión, titulada «Un Guanche, géant de neuf pieds», sobre la obra del bibliotecario y geógrafo inglés Richard Henry Major, editada el año anterior, y de la que incluye un fragmento. En otro número de esta misma revista leemos que Ptolomeo situaba «el diamante más grande del mundo» en la cumbre del Pico del Teide «d'où il projetait ses lueurs sur les mers d'alentour, et cette conception, digne d'un conte oriental, fut regardée comme une vérité géographique par les auteurs de la renaissance» (Charton 1874: 151). Unas líneas más adelante se afirma que fue el cosmógrafo André Thévet quien desveló, en 1578, que esta famosa gema «était tout simplement un cône de neige qui reflétait parfois les rayons du soleil». 
Con el título de «Santa Cruz et La Laguna (Ténériffe)», el historiador occitano Paul Masnou da a conocer una parte de las anotaciones que su padre, oficial médico de la Marina, redacta durante la campaña a China de 1861. Tras la actualización de algunas informaciones, la parte relativa a la escala en Canarias, de apenas un par de días, es editada independientemente en una entrega de 1889 del Bulletin de la Société languedocienne de géographie y con una manifiesta finalidad utilitaria: «Parcourant les notes prises par mon père [...] j'ai cru pouvoir en détacher un article qui pût intéresser la Société» (Masnou 1889: 185). A lo largo de seis páginas, Masnou nos ofrece una imagen que reúne todos los elementos tradicionales del relato de viajes vinculado a Canarias: descripción del aspecto general de la isla -que toma prestada de Jacques Arago-, referencias a la altura del Teide, las calles, casas e iglesias de Santa Cruz de Tenerife, el uso de la mantilla por parte de las mujeres de la clase alta y del pañuelo y el sombrero por las clases más modestas, la presencia de mendigos en la ciudad o la imprescindible excursión a La Laguna, que descubre como una sombría ciudad:

La ville est d'une tristesse inouie: c'est un vrai sépulcre; à peine aperçoit-on deux ou trois personnes dans ces longues et larges rues, et je suppose que, bien aussi grande que Santa Cruz, elle est bien moins peuplée. Les églises et les maisons sont toutes fermées; les magasins doivent pour ainsi dire se deviner; c'est à peine si notre cavalcade bruyante à travers les rues de la ville fait entr'ouvrir quelques portes et soulever quelques jalousies (Masnou 1889: 191).

Esta descripción de la primera capital de Canarias se asemeja bastante a la que un año antes hace el ya mencionado Camille Douls (1888: 180) a propósito de Arrecife:

Lorsqu'on parcourt les rues, on croirait visiter une nécropole; les pas résonnent comme sous une voûte, et c'est à peine si au bruit des pas un volet se soulève de loin en loin, laissant ainsi soupçonner derrière les fenêtres closes l'existence de créatures humaines.

Por otra parte, no hay que olvidar que en las últimas décadas del siglo XIX prolifera un nuevo tipo de viajero -que suele ser de clase acomodada, culto y curioso- que adquiere, paulatinamente, un protagonismo indiscutible: el turista. Algunas sociedades e, incluso, las propias revistas no permanecen ajenas a este hecho y organizan "viajes de estudio» a distintos lugares del mundo. Es el caso de la Revue générale des sciences pures et appliquées, que anuncia, en varias entregas de 1899, el viaje que prepara para abril de ese mismo año con destino a Canarias y Madeira. El director de la publicación, Louis Olivier (15/01/1899a: 1), explica los detalles del recorrido, cuyo objetivo no deja lugar a dudas:

Les voyages de la Revue ne doivent pas seulement permettre aux touristes d'étudier partout les faits d'ordre scientifique: leur portée est plus haute et plus générale: il faut qu'en tout lieu tout ce qui mérite l'attention de l'homme cultivé, qu'il s'agisse de science naturelle, d'histoire, d'art ou de sociologie, lui soit signalé, décrit et expliqué.

Se incluye en esta especie de guía dirigida a los futuros turistas un mapa de Gran Canaria y otro de Tenerife (Olivier 15/01/1899a y 15/01/1899b). Además 
de replicar el itinerario y recomendaciones de Bouquet de la Grye para subir al Teide, se proporciona un listado de obras de utilidad para la preparación del viaje, entre las que se encuentran las de Leclercq (1880), Coquet (1884), Cotteau (1889), Verneau (1891) y Lajard (1891), por solo citar las publicadas en lengua francesa (Olivier 15/01/1899c: 128-129).

En párrafos anteriores hemos tenido la oportunidad de apreciar que la paráfrasis y el calco son técnicas a las que, en este tipo de documentos, suelen recurrir los autores, quienes muchas veces no tienen inconveniente en reconocer sus deudas. En efecto, Paul Tournafond, geógrafo y director de L'Exploration, no solo confiesa que las notas de Théophile Aube le sirven de modelo para su artículo «Les îles Canaries. Histoire, productions, commerce» de 1877, sino que incluso reproduce fragmentos enteros de las ya citadas notas del marino francés. Por su parte, el vizconde y geógrafo-explorador Henri de Bizemont declara, en el apunte que publica en 1881 en la misma revista con el título de «Les îles Canaries», que no es más que un extracto del conocido libro de Jules Leclercq, Voyage aux îles Fortunées (1880). Asimismo, V. H. Demays, colaborador habitual en este tipo de publicaciones, reconoce inspirarse en esta obra a la hora de redactar su pintoresca nota "Les Iles Canaries. Ténériffe», que aparece en el número del 13 de mayo de 1888 del Journal des Voyages et des aventures de terre et de mer. Su portada contiene un grabado titulado «Les Canaries. Un jour de marché à Ténériffe», en el que se representa a una serie de mujeres y campesinos ataviados con la vestimenta tradicional.

Como rezan los prefacios de algunas de las publicaciones, el interés por los viajes y los descubrimientos va más allá del momento presente y alcanza «todos los tiempos». No es extraño, por tanto, encontrar en sus páginas extractos de relatos, cartas y materiales diversos, de carácter informativo o biográfico. Un ejemplo nos lo proporciona el Bulletin de géographie historique et descriptive de 1895, donde podemos leer un interesante artículo de Georges Saint-Yves sobre el astrónomo Louis Feuillée y su viaje a Canarias de 1724, enviado por la Académie des sciences con el fin de determinar la posición exacta de la isla de El Hierro en relación con la del observatorio astronómico de París, establecer la posición de Tenerife y calcular la altura del Teide, temas que ocupan buena parte del trabajo.

Igualmente, los acontecimientos históricos relacionados con el Archipiélago tienen un espacio en algunas publicaciones periódicas. Así, en 1896 Léopold Delisle publica en el Journal des Sçavans una documentada contribución sobre el conocido estudio de Pierre Margry acerca de la conquista de las islas Canarias y sus manuscritos, una cuestión que, lejos de estar agotada, seguía despertando interés en algunos autores y, en consecuencia, en el público lector francés, tal vez por ser dos compatriotas -Jean de Béthencourt y Gadifer de la Salle- quienes iniciaron, en 1402, su toma de posesión en nombre del rey castellano Enrique III.

Se ha de señalar, por último, que no siempre los artículos están firmados con el nombre real de su autor. Es el caso de Maxime Vauvert, seudónimo que se identifica con un grupo de redactores que escribe para diferentes semanarios, 
como Le Journal illustré y Le Monde illustré16. En este último publica, en 1860, «L'île de Ténériffe», una crónica en la que se sirve de la escala de los barcos de guerra franceses con destino a China para realizar una rápida descripción de la isla, que precede de una vista del puerto de Santa Cruz de Tenerife realizada por un oficial de dicha campaña.

\section{Las ilustraciones}

Por otra parte, no podemos dejar de señalar que los dibujos sobre las Islas y sus habitantes que acompañan, con relativa frecuencia, a esta clase de textos merecen una atención especial. Ambos formatos -texto e imagen-comparten espacio y contribuyen a la credibilidad de lo narrado mediante la reproducción fiel de la realidad. Este recurso a la visualización de lo descrito no solo es una práctica habitual en la literatura de viajes, sino que, además, resulta indispensable, en especial cuando se trata de explicar lo exótico y lo distinto. En este contexto, las ilustraciones adquieren un protagonismo indiscutible, pues se apropian del discurso completando lo relatado y ofreciendo, a veces, una interpretación de los lugares, las personas y los hechos (G. de Uriarte 2018a: 261).

Por lo que respecta a la prensa periódica, los grabados en madera de las primeras generaciones tienen, en consonancia con los contenidos que ilustran, un propósito educativo y suelen ofrecer vistas de ciudades, paisajes y muestras de historia natural en las que todavía el viajero no está representado. Será en la segunda mitad del siglo XIX cuando se propaguen los primeros retratos dibujados a partir de fotografías, en cuyo caso el viajero aparece, por lo general, ataviado con la vestimenta tradicional de explorador. Con el paso del tiempo, y de forma gradual, el lector descubre a los miembros de las campañas y sus acompañantes; primero, en un segundo plano, integrados en el paisaje, y, más tarde, ocupando la parte central de la escena, mientras cruzan ríos o atraviesan bosques frondosos, pues las ilustraciones suelen representar etapas importantes, y llamativas, de la expedición. De este modo, para revistas como Le Tour du monde el viajero es, además de una fuente de información, un proveedor de imágenes del mundo (Surun 2007: 63). En un principio, esta iconografía no es original y procede de producciones anteriores o constituye interpretaciones más o menos libres del dibujante, que puede realizar composiciones a partir de materiales publicados en otros relatos de viaje. La aclaración, frecuente, de que el origen de la reproducción es un croquis o una fotografía perteneciente al propio viajero, que se ofrece como prueba indiscutible de veracidad, no impide, sin embargo, su manipulación. En cualquier caso, no cabe duda de que tanto si cumple una función didáctica como si es utilizada con un propósito estético,

16 Georges d'Heylli, en la edición de 1887 de su Dictionnaire des pseudonymes, recoge el nombre de Maxime Vauvert como uno de los apelativos utilizados por los redactores de estas revistas que preferían preservar su identidad. 
la presencia de la imagen convierte la lectura del texto en algo útil y agradable (G. de Uriarte 2018b: 122).

A lo largo de estas páginas hemos hecho alusión en diferentes ocasiones a los dibujos que acompañan a los textos de nuestro corpus. En concreto, contabilizamos una decena de autores que escriben para seis publicaciones diferentes y que proporcionan una veintena de ilustraciones. La mayoría de ellas aparecen en Le Tour du monde, en Le Monde illustré y en el Journal des voyages et des aventures de terre et de mer. Las vistas de las ciudades más relevantes -bien por mérito propio, bien por interés del autor- son las más numerosas, como las estampas que se nos ofrecen de Santa Cruz de Tenerife, La Orotava, Las Palmas de Gran Canaria o Arrecife. El Teide y su cráter o el drago milenario son, igualmente, reproducidos y sobradamente reconocidos por los lectores de libros de viajes. En cuanto a las personas, el isleño, solo o en grupo, está representado por el guía del relato de Cotteau, por el pastor de Mogán del texto de Coupin, así como por las mujeres en el mercado y los campesinos de Demays, ellas elegantemente vestidas, cubiertas con el pañuelo y sombrero típicos, ellos protegidos por la manta.

Llama la atención que las ilustraciones canarias figuren en las portadas de dos relevantes semanarios: La Science pittoresque y el Journal des Voyages et des aventures de terre et de mer. En el primero de ellos encontramos el texto de Curt, «Les Iles Fortunées et le Pic de Ténériffe», que está dividido por una viñeta. Aunque en el pie de la imagen leemos «Pic de Ténériffe», lo cierto es que se trata de una tradicional vista de la costa santacrucera en la que se distinguen varios barcos en un mar en calma y, al fondo, el Teide rodeado de nubes. La segunda portada está ocupada íntegramente por una ilustración titulada «Les Canaries. Un jour de marché à Ténériffe», que antecede el ya mencionado artículo de Demays.

De tamaño variable, las planchas aparecen unas veces integradas en lo escrito y otras, separadas del contenido que ilustran. En estos casos remiten, en el pie, a la página, mientras que el texto reenvía, a su vez, a la ilustración. Los nombres de los dibujantes y grabadores suelen estar, asimismo, mencionados y se cuentan entre los más reconocidos del momento, como Castelli, Girardet, Godefroy, Meunier, Taylor, Thiriat o Vintraut. Este rico y variado material iconográfico pone de manifiesto, por una parte, el interés que siguen despertando las Islas y sus gentes a mediados del siglo xIx; $y$, por otra, el innegable lugar que ocupa la imagen en la escritura del viaje y cuya función no se reduce a la meramente ornamental.

\section{Conclusión}

Este acercamiento a la presencia de Canarias en las publicaciones periódicas francesas en la segunda mitad del siglo XIX aborda una cuestión a la que hasta ahora no se le había dedicado una atención específica.

Como se ha podido observar, en este trabajo hemos distinguido distintos tipos de textos que se materializan en diferentes formatos y modalidades de 
escritura: desde reseñas de libros a informes científicos y académicos, pasando por cartas y apuntes de viaje, hasta estudios especializados o recomendaciones para turistas. En todos ellos se puede apreciar, en mayor o menor medida, que la impresión subjetiva convive con la observación analítica, al igual que sucede en otras formas de la escritura del viaje. En general, se trata de documentos que, por las características y directrices de las revistas, están obligados a ser más bien breves. Se aprecia, por ello, el esfuerzo de síntesis que realizan los autores para poner de relieve aquellos asuntos o aspectos que consideran merecedores de ser destacados, ya sean noticias estrictamente vivenciales o eminentemente utilitarias. Otra peculiaridad que también podemos destacar es que la proximidad con el destinatario se acentúa aún más si cabe cuando es el propio viajero quien comparte directamente sus experiencias y no cuando lo hace de forma indirecta.

La mayoría de los testimonios que hemos sacado a la luz aportan pocas novedades esenciales respecto al conocimiento del Archipiélago o acerca de la realidad insular del momento, salvo en el caso de los estudios sobre el silbo gomero. Sin embargo, constatamos que sí corroboran informaciones ya conocidas, al tiempo que proporcionan nuevas anécdotas y percepciones personales que consiguen, probablemente, una mayor complicidad con el lector. En cualquier caso, el descubrimiento y divulgación de estos materiales, de los que tan solo hemos ofrecido una muestra, permite complementar y enriquecer los estudios existentes sobre las relaciones franco-canarias a la vez que proporciona nuevas líneas de investigación.

\section{Bibliografía}

Alluaud Ch., 1890, «Lettre à M. Le Président», Bulletin de la société zoologique de France, t. XV, n. ${ }^{\circ} 1$, p. $79-81$.

Aube Th., 1876, «Notes sur les Canaries», Revue maritime et coloniale, juillet, s.n., p. 335-347.

Aube Th., 1881, Entre deux campagnes, notes d'un marin, Paris, Berger-Levrault et $\mathrm{C}^{\mathrm{ie}}$.

Aurenche M.-L., 2002, Édouard Charton et l'invention du Magasin pittoresque (1833-1870), Paris, Champion.

Aznar Vallejo E., 2006, «Conquistar y colonizar en las regiones meridionales», in E. Aznar, D. Corbella, B. Pico y A. Tejera (eds.): Le Canarien. Retrato de dos mundos. II. Contextos, La Laguna, Instituto de Estudios Canarios, p. 63-88.

Bacot J.P., 2005, La Presse illustrée au XIX ${ }^{e}$ siècle. Une histoire oubliée, Limoges, Pulim.

Berthelot S., 1861, «Sainte-Croix de Ténériffe...», Comptes rendus hebdomadaires des séances de l'Académie des sciences, t. 53, p. 1265-1267.

Bizemont H. de, 1881, «Les îles Canaries», L'Exploration: journal des conquêtes de la civilisation sur tous les points du globe, t. XI, $1^{\text {er }}$ semestre, p. 302-306. 
Bouquet de la Grye J.-J.-A., 1889, «Une ascension au Pic de Ténériffe», Annuaire pour l'an 1889 publié par le Bureau des longitudes, p. 740-754.

Bouyer F., 1861, «Poulpe géant observé entre Madère et Ténériffe», Comptes rendus hebdomadaires des séances de l'Académie des sciences, t. 53, p. 1263-1265.

C.T. Dr., 1892, «Le langage sifflé», Le Magasin pittoresque, $60^{\circledR}$ année, série 2, t. X, p. 18-19.

Charton É., dir., 1863, «Un monstre marin», Almanach du Magasin pittoresque, $13^{\mathrm{e}}$ année, p. 40.

Charton É., dir., 1872, «Mollusques comestibles de nos côtes. Le poulpe», Le Magasin pittoresque, $40^{\mathrm{e}}$ année, p. 337-339.

Charton É., dir., 1873, «Un Guanche, géant de neuf pieds», Le Magasin pittoresque, $41^{\mathrm{e}}$ année, p. 259.

Charton É., 1874, «Le plus gros diamant du Globe», Le Magasin pittoresque, $42^{\mathrm{e}}$ année, p. 151.

Cibot A., 20/03/1862, «Sainte-Croix de Ténériffe...», Le Monde illustré, 6e année, n. ${ }^{\circ} 259$, p. 208.

Coquet A., 1884, Une excursion aux isles Canaries, Paris, Typographie Georges Chamerot.

Cotteau E., 1889, «Ascension au Pic de Ténériffe (Pic de Teyde)», Le Tour $d u$ monde, n. ${ }^{\circ} 1482$, p. 345-352.

Coupin H., 14/01/1893, «Le langage sifflé», Le Monde illustré, 37e année, n. ${ }^{\circ} 1868$, p. 22-23.

Curell C., J. M. Oliver \& C. G. de Uriarte, 2010, «Gabriel de Belcastel et les débuts du tourisme de santé aux Canaries», in Laurent Tissot (dir.), L'attrait d'ailleurs. Images, usages et espaces du voyage à l'époque contemporaine, Paris, Éditions du Comité des Travaux Historiques et Scientifiques, p. 103-111.

Curt J.H.C., 21/02/1862, «Les Iles Fortunées et le Pic de Ténériffe», La Science pittoresque, 6e année, n. ${ }^{\circ}$ 42, p. 393-395.

Delisle L., 1896, «La conquête et les conquérants des îles Canaries. Nouvelles recherches sur Jean IV de Béthencourt et Gadifer de la Salle. Le vrai manuscrit du Canarien. Par Pierre Margry. Paris. Ernest Leroux. 1896», Journal des Sçavans, s.n., p. 644-659.

Demays V.H., 1888, «Les Iles Canaries. Ténériffe», Journal des Voyages et des aventures de terre et de mer, t. XXII, p. 306-309.

Dietz É., 1883, «Notice sur le Voyage et la correspondance de feu Auguste Stahl, de Sainte-Marie-aux-Mines, attaché à l'expédition française du Gabon (Afrique équatoriale)», Bulletin de la Société académique du Bas-Rhin pour le progrès des sciences des lettres, des arts et de la vie économique, t. XVII, p. 234- 248, 313-330 y 357-372.

Dietz É., 1884, Un explorateur africain. Auguste Stahl, mort au Gabon pendant l'expédition française de 1880. Son voyage et sa correspondance (avec deux cartes). Notice présentée à la Société de Strasbourg, Strasbourg, P. Monnerat. 
Douls C., 1888, «Cinq mois chez les Maures nomades du Sahara occidental», Le Tour du monde, t. LV, p. 177-192.

Dumast [Ch.], 1896, «Aux Canaries», Bulletin de la Société de géographie commerciale de Paris, t. XVIII, 23e année, p. 51-52.

Feyel G., 2001, «Naissance, constitution progressive et épanouissement d'un genre de presse aux limites floues: le magazine», Réseaux 105(1), p. 19-51, <https:// www.cairn-int.info/revue-reseaux1-2001-1-page-19.htm>, consultado el 30/04/2020.

Figuier L., dir., 1863, «Poulpe géant rencontré en pleine mer», L'Année scientifique et industrielle, $7^{\mathrm{e}}$ année, p. 288-292.

Figuier L., dir., 1864, «Pluie de sable aux îles Canaries», L'Année scientifique et industrielle, $8^{\mathrm{e}}$ année, p. 279-280.

Figuier L., 1892, «Le langage sifflé», L’Année scientifique et industrielle, 36e année, p. 305-307.

Gachon P., 1887, «Chronique géographique. Afrique», Bulletin de la Société languedocienne de géographie, t. X, p. 512-517.

G. de Uriarte C., 2006, Literatura de viajes y Canarias. Tenerife en los relatos de viajeros franceses del siglo XVIII, Madrid, Consejo Superior de Investigaciones Científicas.

G. de Uriarte C., 2018a, «El viaje y su ilustración: la función de la imagen en los relatos franceses de viajes (siglos XVI-XIX)», Thélème, revista complutense de estudios franceses, n. ${ }^{o}$ 33(2), p. 259-273, <https://doi.org/10.5209/ THEL.59715>, consultado el 30/04/2020.

G. de Uriarte C., 2018b, «Dibujar el viaje: la iconografía relativa a Canarias en los relatos de viaje franceses del siglo XIX», Studii şi cercetări filologice. Seria limbi romanice, n. ${ }^{\circ} 24$, p. 119-137.

Guentner W., 1997, Esquisses littéraires: rhétorique du spontané et récit de voyage au XIX ${ }^{e}$ siècle, Saint-Genouph, Nizet.

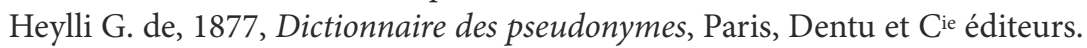

Huerta M., 2007, «Le voyage aux Amériques et les revues savantes françaises au XIX ${ }^{e}$ siècle», Hal archives-ouvertes, <https://halshs.archives-ouvertes.fr/ halshs-00156565>, consultado el 30/04/2020.

Ladero Quesada M.Á., 1979, Los primeros europeos en Canarias (siglos XIV y XV), Las Palmas de Gran Canaria, Mancomunidad de Cabildos Canarios.

Lajard J., 1891, «Le langage sifflé des Canaries», Bulletin de la Société d’Anthropologie de Paris, IVe série, t. 2, p. 469-483.

Le Brun N., 2016, Un francés entre guanches. Sabino Berthelot y las Islas Canarias, La Orotava, LeCanarien ediciones.

Leclercq J., 1880, Voyage aux îles Fortunées, Paris, E. Plon et Cie.

Le Huenen R., 2015, Le récit de voyage au prisme de la littérature, Paris, PUPS.

Magri-Mourgues V., 2009, Le Voyage à pas comptés. Pour une poétique du récit de voyage au XIX $X^{e}$ siècle, Paris, Honoré Champion. 
Malavialle L., 1888, "Chronique géographique. Afrique», Bulletin de la Société languedocienne de géographie, t. XI, p. 217-218 y 357-358.

Malavialle L., 1889, "Chronique géographique. Afrique», Bulletin de la Société languedocienne de géographie, t. XII, p. 446-448.

Malte-Brun V. A., 1867, «La Guyane française. Notes et souvenirs d'un voyage exécuté en 1862-1863, par M. Frédéric Bouyer, capitaine de frégate», Annales des voyages, de la géographie, de l'histoire et de l'archéologie, t. IV, p. 104-116.

Marcil Y., 2006a, La fureur des voyages. Les récits de voyage dans la presse périodique (1750-1789), Paris, Honoré Champion.

Marcil Y., 2006b, «Voyage écrit, voyage vécu? La crédibilité du voyageur, du Journal encyclopédique au Magasin encyclopédique», Sociétés \& Représentations, n. ${ }^{\circ} 21(1)$, p. $23-43$.

Martin L., 2007, «Point de vue sur les images du monde. Voyage, photographie, médias de 1839 à nos jours», Le Temps des médias, n. ${ }^{\circ}$ 8, p. 142-158.

Masnou P., 1889, «Santa Cruz et La Laguna (Ténériffe)», Bulletin de la Société languedocienne de géographie, t. XII, p. 185-191.

Oliver, J.M. (ed.), 2007, «Las Islas Canarias (d)escritas en letras francesas». Nerter. Una revista dedicada a la Literatura, el Arte y el Conocimiento, n. ${ }^{\circ} 11$, p. 7-95.

Oliver J. M. \& C. Curell, 2007a, «Joseph Lajard: El lenguaje silbado de Canarias» [Traducción y notas], in J. J. Batista y M. Morera (eds.), El silbo gomero. 125 años de estudios lingüísticos y etnográficos, Islas Canarias, Academia Canaria de la Lengua, p. 63-75.

Oliver J.M. \& C. Curell, 2007b, «René Verneau: El lenguaje sin palabras» [Traducción y notas], in J. J. Batista y M. Morera (eds.), El silbo gomero. 125 años de estudios lingüísticos y etnográficos, Islas Canarias, Academia Canaria de la Lengua, p. 77-92.

Oliver J.M. \& C. Curell, 2016, «El crucero macaronésico de Jules Verne», in $\mathrm{M}^{\mathrm{a}}$ T. García Castanyer, L. Llecha-Llop Garcia \& A. Piquer Desvaux (eds.), Présences et interférences franco-ibériques: langue, littérature et culture, Bern, Peter Lang, p. 385-396.

Oliver J.M. \& A. Relancio (eds.), 2007, El descubrimiento científico de las Islas Canarias, La Orotava, Fundación Canaria Orotava de Historia de la Ciencia.

Olivier L., dir., 15/01/1899a, "Voyages d'étude de la Revue. Croisière aux Canaries et à Madère en avril 1899», Revue générale des sciences pures et appliquées, t. X, p. 1-2.

Olivier L., 15/01/1899b, «Ténériffe et le Pic du Teyde», Revue générale des sciences pures et appliquées, t. X, p. 87-88.

Olivier L., 15/01/1899c, "Croisière aux Canaries, Madère, Maroc, Espagne et Portugal: livres à lire», Revue générale des sciences pures et appliquées, t. X, p. 128-129. 
Pico B., 2007, «La visita a Tenerife de Edmond Cotteau en 1888», Nerter. Una revista dedicada a la Literatura, el Arte y el Conocimiento, n. ${ }^{\circ} 11$ (J.M. Oliver, (ed.), «Las Islas Canarias (d)escritas en letras francesas»), p. 64-67.

Pico B., D. Corbella, C. G. de Uriarte, C. Curell et al., 2000, Viajeros franceses a las Islas Canarias. Repertorio bio-bibliográfico y selección de textos, La Laguna, Instituto de Estudios Canarios.

Quartapelle A., 2017, «El redescubrimiento de las Islas Canarias en el anno Domini 1339», Revista de Historia Canaria, n. ${ }^{\circ} 199$, p. 11-37.

Relancio Menéndez A. \& M. Ruiz Pacheco (coord.), 2007, Canarias, territorio de exploraciones científicas. Proyecto Humboldt: expediciones científicas a Canarias en los siglos XVIII y XIX, Madrid, Consejo Superior de Investigaciones Científicas.

Saint-Yves G., 1895, «Un voyageur bas-alpin. Le père Louis Feuillée (1660-1732)», Bulletin de Géographie historique et descriptive, p. 302-325.

Serra Ràfols E., 1961, «El descubrimiento de las Islas Canarias en el siglo XIV». Revista de Historia Canaria, t. XXVII, n. ${ }^{\circ} 135-136$, p. 219-234.

Soleillet P., 1880, «Journal d'un voyage du Sénégal à l'Adrar», Bulletin de la Société languedocienne de géographie, t. III, p. 444-492.

Surun I., 2007, «Les figures de l'explorateur dans la presse du XIX ${ }^{e}$ siècle», Le Temps des médias, n. ${ }^{\circ}$ 8(I), p. 57-74, <https://doi.org/10.3917/tdm.008.0057>, consultado el 30/04/2020.

Tournafond P., 1877, «Les îles Canaries. Histoire, productions, commerce», L'Exploration: journal des conquêtes de la civilisation sur tous les points du globe, t. III, p. 7-12.

Valette J., 1980, «Pénétration française au Sahara et exploration: le cas de Paul Soleillet», Revue française d'histoire d'outremer, t. 67, n. ${ }^{\circ} 248-249$, p. 253-267.

Vauvert M., 11/02/1860, "Lîle de Ténériffe», Le Monde illustré, 4e année, n. ${ }^{\circ} 148$, p. 95.

Venayre S., 2007, «Le voyage, le journal et les journalistes au XIX ${ }^{\mathrm{e}}$ siècle», Le Temps des médias, n. ${ }^{\circ} 8$, p. 46-56, <https://doi.org/10.3917/tdm.008.0046>.

Verneau R., 1888a, [Intervención, sin título, del doctor Verneau en las actas de la sesión correspondiente al martes 22 de mayo], Bulletin de géographie historique et descriptive, n. ${ }^{\circ}$ 2, p. 134-137.

Verneau R., 1888b, «Les habitants des îles Canaries», Bulletin de géographie historique et descriptive, n. ${ }^{\circ} 2$, p. 202-210.

Verneau R., 1891, Cinq années de séjour aux Îles Canaries, Paris, A. Hennuyer.

Verneau R., 15/01/1899, «Le Maroc et les Canaries», Revue générale des sciences pures et appliquées, t. X, p. 146-151.

Verneau R., 1923, «Le langage sans paroles», L’Anthropologie, t. XXXIII, p. 161-168.

Weber A. G., 2004, À beau mentir qui vient de loin. Savants, voyageurs et romanciers au XIX ${ }^{e}$ siècle, Paris, Champion. 